\title{
Monitoramento de Correjo Eletrônico Corporativo no Ordenamento Jurídico Brasileiro: Estudos Jurisprudenciais
}

\author{
Lígia Maria Saraiva Barroso \\ Advogada. Consultora em Segurança da Informação. \\ Pós-graduanda em Direito Eletrônico e Tecnologia \\ da Informação pelo Centro Universitário da Grande \\ Dourados (UNIGRAN). Pós-graduanda em Direito \\ Processual pela Faculdade 7 de Setembro (FA7). \\ ligiabarroso@gmail.com
}

Sumário: Introdução. 1. Fundamentos do monitoramento de correio eletrônico corporativo no ordenamento jurídico brasileiro. 2. Monitoramento de correio eletrônico corporativo no Direito Comparado: Estados Unidos e Portugal. 3. Jurisprudência brasileira.

Considerações finais. Referências.

Resumo: O presente trabalho destina-se a explorar as vertentes doutrinárias e jurisprudenciais brasileiras acerca da possibilidade jurídica de monitoramento de correio eletrônico corporativo. Foram trabalhados inicialmente os fundamentos jurídicos mais importantes que justificam a juridicidade de tal prática, tais como fundamentos constitucionais, outros constantes na lei civil brasileira e seus dispositivos acerca da responsabilidade civil, fundamentos constantes na Consolidação das Leis do Trabalho, cujo poder diretivo do empregador é o mais imponente, dentre outros. Buscou-se mostrar, ainda que não sendo o foco principal do estudo, a existência de atos normativos que regulam a segurança da informação na esfera da administração pública, cujo monitoramento de correio eletrônico funcional está entre as práticas. Em um segundo momento, trabalhouse a jurisprudência no Direito Comparado, com decisões proferidas nos Estados Unidos e a posição legal constante no Código de Trabalho português. Finalmente, o estudo segue analisando decisões emitidas pelas mais variadas cortes brasileiras, 
desde a primeira instância até as instâncias superiores, demonstrando a evolução de pensamento e a consolidação do entendimento atual na jurisprudência pátria.

Palavras-chave: Monitoramento Corporativo. Correio Eletrônico. E-mail. Internet. Segurança da Informação.

\section{INTRODUÇÃO}

O presente trabalho destina-se a apurar a aceitabilidade jurídica do monitoramento do correio eletrônico no ambiente corporativo, de acordo com a doutrina e jurisprudência brasileiras, abordando aspectos constitucionais e fundamentos jurídicos para justificar as posições defendidas.

\section{FUNDAMENTOS DO MONITORAMENTO DE CORREIO ELETRÔNICO CORPORATIVO NO ORDENAMENTO JURÍDICO BRASI LEIRO}

Com o advento da internet, observa-se uma crescente virtualização dos meios e das pessoas. O chamado fenômeno da globalização. Através da internet, a praticidade e o dinamismo por ela trazidos vieram a contribuir sobremaneira nas relações comerciais. A facilidade de comunicação obtida através da sua utilização em recursos tais como e-mail, instant messengers, VoIP, dentre outros veio somente a acrescentar aos negócios existentes, agregando-lhes valores.

Hoje vivemos uma realidade em que a internet encontra-se cada vez mais difundida na sociedade, fala-se em direito à internet como um direito fundamental, como pode-se observar nos ensinamentos de Marmelstein (2008, p. 54) "a luta pelo reconhecimento de um direito fundamental à Internet, obrigando o Estado a desenvolver políticas públicas capazes de permitir a inclusão digital de setores economicamente desfavorecidos". Nesse sentido, importante observar as contribuições que a grande rede tem trazido para o desenvolvimento econômico da sociedade. O estabelecimento comercial físico, por exemplo, tornou-se dispensável uma vez que o mesmo pode estar virtualizado, disponível na rede 24 horas por dia todos os dias.

Considerando o atual contexto de difusão e democratização da internet no Brasil e no mundo, e todo o dinamismo e rapidez que a rede proporciona, observa-se a migração de delitos clássicos para o mundo virtual, como a fraude, o estelionato, a calúnia, a difamação e a injúria, dentre outros, além de delitos novos que surgiram a partir da invenção da grande rede.

Com a utilização dos recursos de internet no ambiente corporativo, tendo a finalidade de dinamizar as relações de trabalho e proporcionar comunicação mais rápida e fácil, as empresas abriram espaço para a ocorrência de várias atividades 
que podem prejudicar os seus interesses negociais, desde a utilização dos recursos de internet para fins particulares até o cometimento de crimes através da rede, inclusive os crimes de ordem concorrencial.

Nesse sentido, a preocupação das empresas que vivem a era da informação é manter a sua estrutura tecnológica longe das ameaças geradas a partir do uso inadequado dos recursos computacionais e de internet pertencentes à empresa. Para atingir tal objetivo, somente através de controles que permitam à empresa fiscalizar a utilização de tais recursos, é nesse momento e nesse contexto que se observa a importância do monitoramento de correio eletrônico no ambiente de trabalho.

Através do correio eletrônico podem ser praticadas diversas atividades que podem variar da mera utilização do e-mail corporativo para fins particulares ao repasse de dados estratégicos e sigilosos da empresa para um concorrente, além de difusão de material pornográfico ou de pedofilia, dentre outros delitos.

Percebendo a necessidade de controlar os recursos de acesso à internet fornecido aos empregados, para fins laborais, os empregadores deparam-se com um grande desafio, qual seja: justificar tais controles dentro do contexto do Ordenamento Jurídico e do Estado Democrático de Direito.

Iniciando a pesquisa por fundamentos jurídicos que justifiquem a adoção de métodos de controle de correio eletrônico corporativo, observa-se que a Constituição Federal de 1988 defende, em seu art. 5º o direito à propriedade:

Art. $5^{\circ}$ Todos são iguais perante a lei, sem distinção de qualquer natureza, garantindo-se aos brasileiros e aos estrangeiros residentes no País a inviolabilidade do direito à vida, à liberdade, à igualdade, à segurança e à propriedade, nos termos seguintes: (grifos nossos)

Ao proteger o direito à propriedade, a Constituição Federal garante ao empregador, proprietário da estrutura tecnológica da empresa e, portanto, dono dos computadores, do acesso à internet e das contas de e-mail corporativo proporcionadas aos empregados para a execução de suas atividades profissionais, o direito a fiscalizar a sua utilização.

O Código Civil Brasileiro (Lei 10.406/2002) define, em seu art. 186, o que vem a ser ato ilícito, estabelecendo, posteriormente, a responsabilidade civil pela reparação de danos causados por atos ilícitos no art. 927, dispondo que "Aquele que, por ato ilícito (arts. 186 e 187), causar dano a outrem, fica obrigado a repará-lo":

Art. 186. Aquele que, por ação ou omissão voluntária, negligência, imprudência, violar direito e causar dano a outrem, ainda que exclusivamente moral, comete ato ilícito.

Ainda em relação à responsabilidade civil pela reparação de danos decorrentes de atos ilícitos, o Código Civil Brasileiro dispõe, no art. 932, III, acerca da 
responsabilidade do empregador pelos atos de seus empregados, serviçais e prepostos, quando no exercício do trabalho a que lhes compete ou em razão do mesmo. Tal responsabilidade, por força do art. 933 do citado diploma legal, é objetiva, ou seja, prescinde da apreciação da culpa do empregador para que o mesmo responda pelos atos de seus empregados:

Art. 932. São também responsáveis pela reparação civil:

III - o empregador ou comitente, por seus empregados, serviçais e prepostos, no exercício do trabalho que lhes competir, ou em razão dele

Art. 933. As pessoas indicadas nos incisos I a V do artigo antecedente, ainda que não haja culpa de sua parte, responderão pelos atos praticados pelos terceiros ali referidos.

Silvio de Salvo Venosa esclarece acerca da responsabilidade objetiva do empregador pelos atos de seus empregados:

A responsabilidade do patrão é melhor justificada em sede da teoria do risco. [...] O patrão, ao se valer de um preposto ou de um empregado, está, na verdade, prolongando sua própria atividade. Ainda, o patrão ou preponente assume a posição de garante da indenização perante o terceiro ofendido, porque, na maioria das vezes, o empregado ou preposto não terá meios para reparar o dano. (2006, p.78).

Por sua vez, a Consolidação das Leis do Trabalho (Decreto-Lei n 5452/43) em seu art. $2^{\circ}$, garante ao empregador o Poder Diretivo, através do qual "Considera-se empregador a empresa, individual ou coletiva, que, assumindo os riscos da atividade econômica, admite, assalaria e dirige a prestação pessoal de serviço".

O poder de direção consiste na faculdade do empregador de organizar a execução da atividade laboral dos empregados. É doutrinariamente dividido em três aspectos, quais sejam, o poder disciplinar, o poder regulamentar e o poder de fiscalização, o qual compreende o monitoramento de correio eletrônico. Segundo as considerações de Alice Monteiro de Barros:

A autoridade do empregador exterioriza-se pelo poder de direção e torna-se efetiva pelo poder disciplinar. Outros autores alinham a estes dois o poder regulamentar e o consideram como manifestação da autoridade empresarial, que se configura como um poder de legislar no âmbito da empresa. (2009, p. 583) (grifos nossos)

O fundamento jurídico mais eloquente acerca da possibilidade de monitoramento de correio eletrônico corporativo pelos respectivos empregadores consiste no poder de fiscalização e controle conferidos ao empregador em decorrência do poder de direção. Dessa forma, sendo o empregador o proprietário dos computadores, do acesso à internet e do serviço de correio eletrônico adotado pela empresa, e fornecendo toda essa estrutura tecnológica para atender atividades estritamente profissionais, o empregador, 
baseado no poder de controle, tem o direito de monitorar a utilização dos recursos em questão, com a finalidade de constatar a sua correta utilização.

Tais argumentos têm fundamento na teoria da propriedade privada, a mesma sendo utilizada para fundamentar a existência do poder diretivo e disciplinar, a qual afirma, segundo Barros (2009, p. 584), que "esse poder conferido ao empregador reside no fato de ser a empresa objeto do seu direito de propriedade, logo, o empregador comanda porque é dono."

Há também a edição da norma técnica NBR ISO IEG 27002, traduzida e publicada oficialmente no Brasil pela Associação Brasileira de Normas Técnicas, a qual elenca um rol de boas práticas em Segurança da Informação e reserva um capítulo específico para tratar de monitoramento de correio eletrônico, o que indica como conveniente, sob o seguinte teor:
Monitoramento
Objetivo: Detectar atividades não autorizadas de processamento de informação.
Convém que os sistemas sejam monitorados e eventos de segurança da informação sejam registrados.
Convém que registros (log) de operador e registros (log) de falhas sejam utilizados para assegurar que os problemas de sistemas de informação são identificados.
Convém que as organizações estejam de acordo com todos os requisitos legais relevantes aplicáveis para suas atividades de registro e monitoramento.
Convém que o monitoramento do sistema seja utilizado para checar a eficácia dos controles adotados e para verificar a conformidade com o modelo de política de acesso.

Além dos fundamentos jurídicos em questão, aplicáveis à iniciativa privada, ressalta-se que a Administração Pública também visualizou a necessidade de se disciplinar a utilização de recursos tecnológicos fornecidos aos servidores públicos para execução de suas atividades. Nesse sentido, além dos fundamentos jurídicos constitucionais levantados e das disposições do Código Civil sobre responsabilidade civil, cabe ressaltar a necessidade de observância a alguns quesitos que justificam a adoção de mecanismos de controle pela Administração Pública.

A Constituição Federal estabelece, em seu art. 37, os princípios da administração pública: Legalidade, Impessoalidade, Moralidade, Publicidade e Eficiência, os quais, quando levados ao contexto laboral, guardam estreita ligação com a correta utilização dos recursos públicos fornecidos aos servidores para a melhor prestação do serviço. Dessa forma, a adoção de métodos de monitoramento de correio eletrônico alcançaria o objetivo de fiscalização da correta utilização do recurso, além de servir como meio de detecção de atividades não autorizadas, fazendo, inclusive, prova hábil a instruir eventuais processos administrativos ou judiciais.

Há também a edição de decretos, em sede das respectivas administrações, federal e estaduais, com o objetivo de proteção dos acervos informacionais dos respectivos órgãos através da regulamentação do uso dos recursos tecnológicos. Alguns exemplos 
desses decretos são o Dec. n 3505/2000, da Administração Pública Federal; o Dec. n 29.277/2008 do Estado do Ceará e o Dec. n 44.998/2008 do Estado de Minas Gerais.

\title{
2 MONITORAMENTO DE CORREIO ELETRÔNICO CORPORATIVO NO DIREITO COMPARADO: ESTADOS UNIDOSE PORTUGAL
}

A discussão acerca da aceitabilidade jurídica do monitoramento de correio eletrônico corporativo pelo empregador, diferentemente do Brasil, já existe há alguns anos, em países como Estados Unidos, cujas decisões judiciais acerca do conflito privacidade dos empregados e poder de controle dos empregadores já movimentavam os tribunais americanos no início da década de noventa.

No conhecido leading case B ourke v. Nissan M otor Corp., datado de 1993, pode-se observar os argumentos aceitos pela corte que apreciou a causa nos seguintes fragmentos:

\begin{abstract}
Whether an individual's constitutional right to privacy has been violated depends first on a determination whether that individual had a personal and objectively reasonable expectation of privacy which was infringed. Nissan maintains that the evidence conclusively establishes that plaintiffs had no reasonable expectation of privacy in their E-mail messages. In support of this contention, they cite the following undisputed facts: (1) Plaintiffs each signed a Computer User Registration Form, which states that " [] $\mathrm{t}$ is company policy that employees and contractors restrict their use of company-owned computer hardware and software to company business."

Nissan contends that the foregoing uncontroverted facts regarding plaintiffs knowledge that E-mail messages could in fact be read without the author's knowledge or consent establishes as a matter of law that plaintiffs had no objectively reasonable expectation of privacy in those messages. In contradiction of that conclusion, plaintiffs assert that they had such an expectation becausethey weregiven passwords to access the computer system and were told to safeguard their passwords.

In the absence of a reasonable expectation of privacy, there can be no violation of the right to privacy. Thus, plaintiffs' causes of actions for common law invasion of privacy and violation of the constitutional right to privacy were properly dismissed on summary judgment. (grifos nossos) $(2009 \text {, online) })^{1}$.
\end{abstract}

\footnotetext{
Se o direito constitucional à privacidade de um indivíduo for violado, depende, em primeiro lugar, se o mesmo tinha uma expectativa pessoal e objetivamente razoável de privacidade que foi violada. Nissan afirma que a evidência estabelece conclusivamente que os reclamantes não tinham nenhuma expectativa razoável de privacidade sobre seus e-mails. Em apoio a esta tese, ela cita os fatos incontroversos: (1) Cada reclamante assinou um Termo de Uso de Sistemas de Informação, que estabelece que " $\Pi$ É política da empresa que a utilização de hardware e softwares de computador de propriedade da empresa por parte de empregados e terceiros seja restrita aos interesses da empresa."
} 
Baseando-se no argumento de que todos os funcionários teriam assinado um documento de registro de usuários de computadores da empresa e que o mesmo estabelecia que a utilização dos recursos computacionais da empresa eram restritos a assuntos profissionais, a reclamada, Nissan, argumenta que a reclamante não possuía nenhuma expectativa de privacidade quanto à utilização dos computadores da empresa. A reclamante, por sua vez, argumenta que o fato de as contas de e-mail corporativo, fornecidas pela empresa, possuírem senhas e serem os empregados orientados a guardar tais senhas sob sigilo, ensejava tal expectativa de privacidade.

A corte americana decidiu pela improcedência da reclamação, por não visualizar expectativa de privacidade razoável que ensejasse a reclamante a acreditar não ser possível que a empresa monitorasse sua conta de correio eletrônico corporativo.

No caso Smyth v. Pillsbury Company, a corte Americana proferiu decisão a favor da empresa reclamada, defendendo que a prática do monitoramento de correio eletrônico, com a função de prevenir utilização inadequada e não profissional ou até para atividades ilegais da ferramenta de e-mail corporativo, se sobrepõe à privacidade que o empregado tenha interesse em preservar. Tal entendimento demonstra a preocupação dos magistrados em aplicar a técnica da ponderação diante de argumentos que versem sobre o conflito de direitos fundamentais, como o direito à propriedade e o direito à privacidade. Além disso, pode-se observar uma prevalência do interesse público em detrimento da proteção absoluta ao direito fundamental à privacidade pretendido pela parte reclamante.

In the second instance, even if we found that an employee had a reasonable expectation of privacy in the contents of his e-mail communications over the companye-mail system, wedo not find that a reasonableperson would consider the defendant's interception of these communications to bea substantial and highly offensive invasion of his privacy. A gain, we note that by intercepting such communications, the company is not, as in the case of urinalysis or personal property searches, requiring the employeeto discloseany personal information about himself or invading the employee's person or personal effects. M oreover, the company's interest in preventing inappropriate and unprofessional comments or even illegal activity over its e-mail system outweighs any privacy interest the employee may have in those comments. ${ }^{2}$ (grifos nossos) (2009, online).

\footnotetext{
Nissan alega que os fatos acima incontroversos sobre o conhecimento dos demandantes de que o e-mail poderia na verdade ser lido sem o conhecimento ou consentimento do autor estabelece como uma questão de direito que os reclamantes não tinham expectativa objetivamente razoável de privacidade nessas mensagens. Em contradição com essa conclusão, os reclamantes afirmam que eles tinham essa expectativa, porque eles receberam senhas para acessar o sistema do computador e foram instruídos a proteger suas senhas.

$\mathrm{Na}$ ausência de uma expectativa razoável de privacidade, não haverá violação do direito à privacidade. Assim, as causas dos demandantes das ações de common law por invasão de privacidade e violação do direito constitucional à privacidade foram devidamente indeferidas em julgamento sumário (tradução nossa).

2 Em segunda instância, mesmo que entendêssemos que um funcionário tinha uma expectativa razoável de privacidade no conteúdo de suas comunicações através de sistema de correio eletrônico da empresa, nós não achamos que uma pessoa razoável consideraria a intercepção destas comunicações uma invasão
} 
Observa-se em ambas as decisões que o argumento principal para a aceitação do monitoramento do e-mail em detrimento da privacidade do empregado reside no fato de os empregadores, previamente, terem dado ciência a seus empregados quanto à utilização do correio eletrônico corporativo exclusivamente para fins profissionais e da possibilidade de controle sobre tais recursos. Nesse sentido, Lélia Guimarães Carvalho Ribeiro:

É sempre necessário que o empregador ou seus prepostos dêem ciência aos trabalhadores do conteúdo da norma interna da empresa, após fixá-la em um lugar bem visível a todos, além de comunicar ao sindicato competente tais medidas. (2008, p. 126)

Semelhante à tendência permissiva americana quanto à aceitabilidade jurídica do monitoramento de correio eletrônico corporativo, notamos na legislação portuguesa posicionamento favorável ao monitoramento de correio eletrônico corporativo, em alguns casos, conforme pode-se observar no disposto no Código do Trabalho português:

Artigo 21. ${ }^{\circ}$

Confidencialidade de mensagens e de acesso a informação

1 - O trabalhador goza do direito de reserva e confidencialidade relativamente ao conteúdo das mensagens de natureza pessoal e acesso a informação de carácter não profissional que envie, receba ou consulte, nomeadamente através do correio electrónico.

2 - O disposto no número anterior não prejudica o poder de o empregador estabelecer regras de utilização dos meios de comunicação na empresa, nomeadamente do correio electrónico. (online)

Por todo o exposto, observa-se uma postura permissiva dos ordenamentos jurídicos exemplificados quanto à possibilidade de realização de monitoramento de correio eletrônico no ambiente de trabalho, quando o mesmo for utilizado para fins profissionais e for fornecido pelo empregador como ferramenta de trabalho. Vejamos a postura da doutrina e jurisprudência brasileira a respeito.

\footnotetext{
substancial e altamente ofensiva da sua privacidade. Novamente, notamos que ao interceptarmos tais comunicações, a empresa não está, como no caso do exame de urina ou no de revistas de bens pessoais, requisitando do empregado que divulgue qualquer informação pessoal sobre si ou invadindo a pessoa do trabalhador ou sua esfera privada. Além disso, o interesse da empresa em prevenir que comentários inapropriados, não profissionais ou até atividades ilegais sejam praticados através da utização de seu sistema de e-mail sobrepõe-se a qualquer interesse privado que o empregado tenha sobre tais comentários (tradução nossa).
} 


\section{JURISPRUDÊNCIA BRASILEIRA}

Apesar de a matéria em questão já vir sendo amplamente discutida nas cortes americanas desde o início da década de 90, no Brasil, a mesma só veio tomar relevância nos tribunais quando noticiada decisão proferida pelo juiz da $13^{\mathrm{a}}$ Vara do Trabalho de Brasília, em que defendia o correio eletrônico como correspondência e decidiu pela proteção da inviolabilidade do mesmo, conforme observa-se no trecho:

\section{TRIBUNAL REGIONAL DO TRABALHO $10^{\mathrm{a}}$ REGIÃO $13^{\text {a }}$ VARA DO TRABALHO DO DISTRITO FEDERAL}

A inviolabilidade da correspondência tutelada constitucionalmente é absoluta, pois a única exceção feita pelo próprio dispositivo constitucional é atinente à comunicações telefônicas, quando, por ordem judicial, se destinarem à investigação criminal ou instrução processual penal. (TRT - DF Processo n: 13.000613/2000, Juiz José Leone Cordeiro Leite - $13^{\circ}$ Vara do Trabalho)

Em razão do entendimento do magistrado fundamentado em tal decisão, tomaria a jurisprudência brasileira entendimento diverso de tantos outros países que já vinham tratando da questão há muito mais tempo? A decisão em comento logo foi reformada pelo respectivo Tribunal Regional do Trabalho de Brasília, em segunda instância, pelo que se observa do disposto na ementa:

\section{TRIBUNAL REGIONAL DO TRABALHO $10^{\mathrm{a}}$ REGIÃO}

Ementa: Justa Causa. E-mail. Prova Produzida por Meio Ilícito. Não ocorrência.

Quando empregado comete um ato de improbidade ou mesmo um delito utilizando-se do e-mail da empresa, esta, em regra, responde solidariamente pelo ato praticado por aquele. Sob este prisma, podemos então constatar quão grave e delicada é esta questão, que demanda a apreciação jurídica dos profissionais do Direito. Enquadrando tal situação à Consolidação das Leis do Trabalho, verifica-se que tal conduta é absolutamente imprópria, podendo configurar justa causa para a rescisão contratual, dependendo do caso e da gravidade do ato praticado. Considerando que os equipamentos de informática são disponibilizados pelas empresas aos seus funcionários com a finalidade única de atender às suas atividades laborativas, o controle do e-mail apresenta-se como a forma mais eficaz, não somente de proteção ao sigilo profissional, como de evitar o mau uso do sistema Internet que atenta contra a moral e os bons costumes, podendo causar à empresa prejuízos de larga monta. (RO 0504/2002 Tribunal Regional do Trabalho da $10^{a}$ Região. Relatora: Juíza Márcia Mazoni Cúrcio Ribeiro - Revisor: Juiz Douglas Alencar Rodrigues)

Após esse desfecho, observa-se que a mesma linha de raciocínio vem sendo usada na fundamentação de outras decisões judiciais sobre demandas que versam sobre a possibilidade de monitoramento de recursos de correio eletrônico corporativo. Nesse sentido, observa-se outra decisão a respeito da mesma matéria: 


\begin{abstract}
TRIBUNAL REGIONAL DO TRABALHO $2^{\text {a }}$ REGIÃO ACÓRDÃO No 20060375633 RO

EMENTA: Endereço eletrônico fornecido pelo empregador se equipara a ferramenta de trabalho e não pode ter seu uso desvirtuado pelo empregado. Pertencendo a ferramenta ao empregador, a esse cabe o acesso irrestrito, já que o empregado detém apenas a sua posse.
\end{abstract}

O Tribunal Superior do Trabalho também se manifestou a respeito nos autos do Recurso de Revista 9961/2004, proferindo decisão cujo fundamento foi o mesmo da decisão supracitada, equiparando o correio eletrônico profissional a uma ferramenta de trabalho. Sendo, portanto, garantido ao empregador pleno acesso a tal ferramenta, para verificar se a mesma está sendo utilizada corretamente.

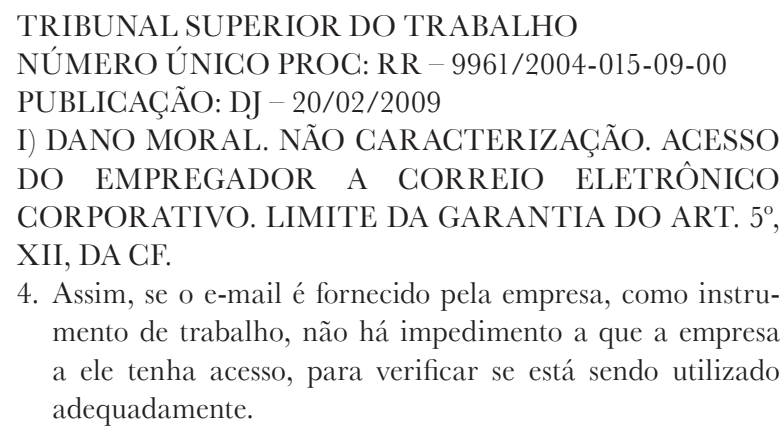

Além de verificação quanto à correta utilização de recursos de comunicação eletrônica fornecidos aos empregados pelos respectivos empregadores, a utilização dos meios eletrônicos envolve outros riscos legais que necessitam ser considerados pelos empregadores, por força da legislação civil que impõe responsabilidade civil objetiva aos mesmos pelos atos de seus empregados e prepostos, considerando que o e-mail pode ser utilizado como ferramenta para disseminação de calúnias e difamações, além do cometimento de crimes e outras práticas delituosas tais como racismo, discriminação, concorrência desleal, violação de sigilo funcional, dentre outras.

A jurisprudência em destaque traz decisão proferida no processo $\mathrm{n}^{\circ}$ 012.0058.2008, cujo reclamante pleiteia indenização por danos morais de seu empregador, decorrentes do recebimento de e-mail de conteúdo racista, enviado pelo seu superior hierárquico, através da conta de correio eletrônico corporativo.

\footnotetext{
TRIBUNAL REGIONAL DO TRABALHO $10^{a}$ REGIÃO

PROCESSO N ${ }^{\circ}$ 012.0058.2008

$[\ldots]$

Conforme identificado nos autos, o supervisor da reclamada, superior hierárquico do autor, respondendo justificativa promovida pelo reclamante, enviou-lhe o e-mail de fls. 50 assim disposto. Verbis.
} 


\begin{abstract}
"OK Sr. XXXX, pelo tipo de pele entendo a sua colocação. Este é um fato típico da senzala!!! Nós que somos de cútis mais clara não compreendemos certas considerações até porque não possuímos correntes atadas aos pés ou sofremos qualquer tipo de chibatadas quando ocorremos em fatos errados, o que não é normal, para nós HUMANOS"

[...] a classificação da ofensa moral é da maior gravidade ante tamanho descalabro de cunho racista, humilhante e vexatório, cuja dimensão mundial da empregadora somente agrava tal prática discriminatória, pois, a meu sentir, revela-se majorada a obrigação patronal da fiscalização laboral e do respeito profissional e humano entre seus subordinados ou perante terceiros pela projeção elastecida da empresa, gerando, por óbvio, maior repercussão profissional e no sentimento íntimo do autor e perante colegas de uma empresa de tamanha proporção que atua no território nacional. [...]

Por conseguinte, condeno o reclamado ao pagamento da indenização no importe de $\mathrm{R} \$ 268.348,00$ a título de danos morais em favor do autor, sem prejuízo das atualizações de direito.
\end{abstract}

Diante de tal cenário, resta confirmada a necessidade de avaliação das circunstâncias, da relativização de direitos fundamentais tais como a intimidade e a privacidade ante a propriedade e igualdade de tratamento e vedação do racismo e da discriminação através da técnica da ponderação.

Por óbvio que a situação específica trazida para análise no presente estudo vem demonstrar que tal análise de ponderação já se encontra de certa forma sedimentada na jurisprudência pátria, e que a solução encontrada através da ponderação dos argumentos defendidos para autorizar ou não o monitoramento de correio eletrônico por parte do empregador está condensada na decisão do ministro João Oreste Dalazen a seguir:

TRIBUNAL SUPERIOR DO TRABALHO

PROVA ILÍCITA - E-MAIL CORPORATIVO - JUSTA CAUSA -

DIVULGAÇÃO DE MATERIAL PORNOGRÁFICO

1. Os sacrossantos direitos do cidadão à privacidade e ao sigilo de correspondência, constitucionalmente assegurados, concernem à comunicação estritamente pessoal, ainda que virtual (e-mail particular). Assim, apenas o e-mail pessoal ou particular do empregado, socorrendo-se de provedor próprio, desfruta da proteção constitucional e legal de inviolabilidade. 2. Solução diversa impõe-se em se tratando do chamado e-mail corporativo, instrumento de comunicação virtual mediante o qual o empregado louva-se de terminal de computador e de provedor da empresa, bem assim do próprio endereço eletrônico que lhe é disponibilizado igualmente pela empresa. (TST RR 613/00.7 - 1 ${ }^{\text {a }}$ T. - Rel. Min. João Oreste Dalazen - DJU 10.06.2005) (grifos nossos)

No entanto, para se fazer valer a possibilidade de monitoramento de correio eletrônico profissional, o empregador deverá certificar-se de que os empregados estão cientes de tal prática. Este é o requisito essencial para se fazer valer o monitoramento em questão. 
Em contrapartida, em respeito ao direito à privacidade e à intimidade do trabalhador, o empregador deverá se abster de monitorar o conteúdo de mensagens enviadas ou recebidas através de contas de correio eletrônico particulares, pois estas sim, estão protegidas juridicamente contra as invasões arbitrárias. Para que sejam evitados problemas no âmbito corporativo em relação a tais contas de correio eletrônico particulares, é recomendável que o acesso a esse tipo de serviço seja bloqueado.

\section{CONSI DERAÇÕES FINAIS}

Tendo finalizado a investigação proposta, resta estabelecer as conclusões alcançadas:

Quanto aos fundamentos jurídicos que possibilitam a adoção da prática do monitoramento de correio eletrônico corporativo no ordenamento jurídico brasileiro, temos os seguintes argumentos:

a) O direito à propriedade consolidado no art. $5^{\circ}$ da Constituição Federal de 1988;

b) Os artigos do Código Civil Brasileiro que dispõem sobre atos ilícitos, responsabilidade civil e responsabilidade civil objetiva do empregador pelos atos de seus empregados e prepostos quando da execução do serviço;

c) $\mathrm{O}$ poder diretivo do empregador, consolidado no art. $2^{\circ}$ da Consolidação das Leis do trabalho;

d) O disposto na norma técnica NBR ISO IEC 27002 sobre boas práticas de segurança da informação;

e) Decreto federal n 3505/2000 sobre segurança da informação e os respectivos decretos estaduais.

Todos esses argumentos servem para consolidar a possibilidade de os empregadores efetivamente estabelecerem práticas de segurança e controle quanto a seus sistemas de informação, utilização de internet e correio eletrônico corporativo fornecidos a seus empregados para realização de suas respectivas tarefas profissionais.

Quanto ao Direito comparado, observou-se que, nos Estados Unidos, a jurisprudência vem apreciando demandas trabalhistas envolvendo o monitoramento de correio eletrônico corporativo há mais de uma década, consolidando entendimento no sentido de que estando ciente o empregado da ausência de expectativa de privacidade na utilização dos recursos tecnológicos da empresa, inclusive o correio eletrônico, a empregadora poderá monitorar tais recursos.

Em Portugal, observou-se no Código do Trabalho português a preocupação em dispor legalmente sobre o tema, conferindo ao empregador a possibilidade de monitorar e controlar os recursos tecnológicos que disponibiliza a seus empregados, desde que de uso exclusivamente profissional. A legislação portuguesa protege a privacidade de mensagens de caráter pessoal, no entanto dá ao empregador a possibilidade de 
estabelecer as regras de utilização do correio eletrônico, podendo este proibir a utilização de cunho particular.

No Brasil, observou-se um posicionamento firmado pela jurisprudência trabalhista no sentido de proteger a privacidade de mensagens e contas de correio eletrônico particulares. Podendo o empregador tão somente monitorar as contas de e-mail corporativo, por ter este recurso natureza de ferramenta de trabalho.

\section{REFERÊNCIAS}

BARROS, Alice Monteiro de. Curso de direito do trabalho. 5. ed. rev. e ampl. São Paulo: LTr, 2009.

BRASIL. Constituição (1988). Constituição da República Federativa do Brasil. Brasília, DF, Senado, 1988.

BRASIL. Lei n ${ }^{\circ}$ 10.406, de 10 de janeiro de 2002. Código Civil Brasileiro, Brasília, DF, Senado, 2002.

BRASIL. Tribunal Regional do Trabalho (2 Região). Recurso Ordinário nº 014782004-067-02-00-6. Recorrente: Elaine Vicente Raia Recorrida: Nestlé Brasil LTDA. Relatora: Jane Granzoto Torres da Silva. São Paulo, 23 de junho de 2006. Disponível em: <http://www.trt02.gov.br:8035/020060375633.html>. Acesso em: 08 jan. 2010.

BUSCALEGIS. Comentários à jurisprudência: justa causa. E-mail. Prova produzida por meio ilícito. Não ocorrência. 3ậTurma do Tribunal Regional do Trabalho do Distrito Federal. Disponível em: <http://www. buscalegis.ufsc.br/revistas/index.php/buscalegis/article/viewFile/5374/4943>. Acesso em: 08 jan. 2010.

JUSNAVIGANDI. Comentários à jurisprudência: justa causa. E-mail. Prova produzida por meio ilícito. Não ocorrência. 3ậurma do Tribunal Regional do Trabalho do Distrito Federal. Disponível em: <http://jus2.uol. com.br/doutrina/texto.asp?id=3337\&p=2>. Acesso em: 08 jan. 2010.

LEONARDI, Marcel. Direitoel nternet Decisão TST - RR - 9961/2004-015-09-00. Disponível em: <http://www.leonardi.adv.br/blog/decisao-tst-rr-99612004-015-09-00/>. Acesso em: 08 jan. 2010.

LEONARDI, Marcel. Direito e Internet. Decisão TRT10 - 00708-2007-014-10-00-3. Disponível em: <http://www.leonardi.adv.br/blog/decisao-trt10-00708-2007-014-10-00-3/>. Acesso em: 08 jan. 2010. 
LOUNDY. Smyth v. Pillsbury Company. Disponível em: <http://www.loundy. com/CASES/Smyth_v_Pillsbury.html>. Acesso em: 15 dez. 2009.

MARMELSTEIN, George. Curso dedireitosfundamentais، São Paulo: Atlas, 2008.

MTSS. Código do trabalho. Disponível em: <http://www.mtss.gov.pt/docs/Cod_ Trabalho.pdf>. Acesso em: 15 dez. 2009.

PROTOCOLO JURÍDICO. E-mail com teor racista. Disponível em: <http:// protocolojuridico.com.br/index2.php?option=com_content\&do_pdf $=1 \& i d=192>$. Acesso em: 08 jan. 2010.

RIBEIRO. Lélia Guimarães Carvalho. Amonitoração audiovisual e eletrônica no ambiente de trabalho e seu valor probante: um estudo do poder de controle do empregador na atividade laboral e o respeito à dignidade e intimidade do trabalhador. São Paulo: LTr, 2008.

TOMWBELL. Bourke v. Nissan Motor Corp. in USA. Disponível em: <http:// www.tomwbell.com/NetLaw/Ch05/Bourke.html>. Acesso em: 15 dez. 2009.

\title{
CORPORATE E-MAIL MONITORING IN BRAZIL: JURISPRUDENTIAL STUDIES
}

\begin{abstract}
This paper has the purpose of exploring the Brazilian legal doctrine and jurisprudence about the juridical possibility of corporate e-mail surveillance. Initially the most important juridical fundaments were focused to justify such practices, under constitutional and Labor Law fundaments, for example. Even though it is not the main subject of the study, it was sought to show the existence and effectiveness of such normative acts that regulate information security in the public administration, such as e-mail surveillance. Later, Comparative Law jurisprudence was brought in, with sentences from the United States system and the Labor Courts from Portugal. Finally, the study analyses several Brazilian court decisions, from different instances, presenting the evolution of the thought and the recent unification of understanding in this country's courts.
\end{abstract}

Keywords: Corporative monitoring. E-mail. Internet. Information security. 